\title{
Peripheral effects of vagus nerve stimulation on anxiety and extinction of conditioned fear in rats
}

\author{
Lindsey J. Noble, ${ }^{1,2}$ Ashleigh Chuah, ${ }^{1}$ Kathleen K. Callahan, ${ }^{1}$ Rimenez R. Souza, ${ }^{1,2}$ \\ and Christa K. Mclntyre ${ }^{1,2}$ \\ ${ }^{1}$ School of Behavior and Brain Sciences, The University of Texas at Dallas, Richardson, Texas 75080-3021, USA; ${ }^{2}$ Texas Biomedical \\ Device Center, The University of Texas at Dallas, Richardson, Texas 75080-3021, USA
}

\begin{abstract}
Vagus nerve stimulation (VNS) enhances extinction of conditioned fear in rats. Previous findings support the hypothesis that VNS effects on extinction are due to enhanced consolidation of extinction memories through promotion of plasticity in extinction-related brain pathways however, alternative explanations are plausible. According to one hypothesis, VNS may produce a hedonic effect and enhance extinction through counter-conditioning. According to another hypothesis, VNS reduces anxiety during exposure and this weakens the association of conditioned stimuli with aversive conditioned responses. The present set of experiments (1) used conditioned place preference (CPP) to identify potential rewarding effects associated with VNS and (2) examined the peripheral effects of VNS on anxiety and extinction enhancement. Male Sprague-Dawley rats were surgically implanted with cuff electrodes around the vagus nerve and subjected to a CPP task in which VNS and sham stimulation were each paired with one of two distinct contexts over the course of $5 \mathrm{~d}$. Following this procedure, rats did not show a place preference, suggesting that VNS is not rewarding or aversive. The role of the peripheral parasympathetic system in the anxiolytic effect of VNS on the elevated plus maze was examined by blocking peripheral muscarinic receptors with intraperitoneal administration of methyl scopolamine prior to VNS. Methyl scopolamine blocked the VNS-induced reduction in anxiety but did not interfere with VNS enhancement of extinction of conditioned fear, indicating that the anxiety-reducing effect of VNS is not necessary for the extinction enhancement.
\end{abstract}

Exposure-based therapies are considered the "gold standard" approach to the treatment of posttraumatic stress disorder (PTSD) (Rauch et al. 2012). Rather than treating symptoms alone, exposure therapy provides opportunities to extinguish conditioned fear associations (Bouton 1988; Ressler et al. 2004; Davis et al. 2006; Powers et al. 2009). However, exposure therapy is not effective in all patients and many drop out (Schottenbauer et al. 2008; Garcia et al. 2011; Najavits 2015) or relapse after completing therapy (Boschen et al. 2009; Vervliet et al. 2013). We have attempted to target the same mechanisms that contribute to the enhancement of emotionally arousing memories in order to promote extinction memories that can compete with the memory of the trauma. During times of heightened emotional arousal, the brain signals the adrenal gland to release epinephrine into the bloodstream. This adrenergic response results in improvements in the ability to fight, or flee from danger. The increase in epinephrine also appears to contribute to the enhancement of emotionally arousing memories (Gold et al. 1975, 1977; Cahill and Alkire 2003). However, because epinephrine does not freely cross the blood-brain barrier, it cannot directly influence memory substrates in the brain. One pathway by which epinephrine may interact with the brain is through the 10th cranial nerve. The vagus nerve responds to peripheral administration of epinephrine (Miyashita and Williams 2006; Chen and Williams 2012) and stimulation of the vagus nerve increases norepinephrine levels in the amygdala (Hassert et al. 2004), and enhances memory in rats (Clark et al. 1995, 1998) and in humans (Clark et al. 1999). Blocking norepinephrine receptors in the amygdala prevents the memory enhancing effects of epinephrine administration (Liang et al. 1986),

\section{Corresponding author: christa.mcintyre@utdallas.edu}

Article is online at http://www.learnmem.org/cgi/doi/10.1101//m.048447.118. indicating that the vagus nerve serves as a bridge between the peripheral stress response and noradrenergic signaling in the brain that modulates the consolidation of emotionally arousing memories.

Vagus nerve stimulation (VNS) enhances the consolidation of extinction memories in rats (Peña et al. 2013; Alvarez-Dieppa et al. 2016; Noble et al. 2018), and it accelerates extinction of conditioned fear and attenuates reinstatement in a rat model of PTSD (Noble et al. 2017), suggesting that VNS could be used to augment the effects of exposure-based therapies in treatment of PTSD and other disorders. VNS may provide an added benefit of reducing anxiety during therapy. Chronic VNS reduces anxiety in rats (Furmaga et al. 2011; Shah et al. 2016) and in humans (George et al. 2008), and we recently found that short-term administration of VNS increased the time that rats spent in the open arms of an elevated plus maze (EPM) (Noble et al. 2019). The vagus nerve is part of the parasympathetic peripheral nervous system and it is called the "vagal brake" because it counteracts the sympathetic effects of stress on the heart and other organs. Although the left cervical vagus nerve is composed of $80 \%$ afferent fibers and only $20 \%$ efferent fibers, it is possible that peripherally mediated effects contribute to VNS enhancement of extinction memory. The peripheral parasympathetic effects of VNS may interfere with sympathetic responses to conditioned stimuli (CS); potentially altering the association of trauma reminders with the expected stress response.

In addition to signaling the brain during times of heightened stress, the vagus nerve relays information from the gut to the brain.

(C) 2019 Noble et al. This article is distributed exclusively by Cold Spring Harbor Laboratory Press for the first 12 months after the full-issue publication date (see http://learnmem.cshlp.org/site/misc/terms.xhtml). After 12 months, it is available under a Creative Commons License (Attribution-NonCommercial 4.0 International), as described at http://creativecommons.org/licenses/by-nc/4.0/. 
In a recent study, optical stimulation of the right vagal sensory ganglion in mice promoted self-stimulation behavior, drove a conditioned place and flavor preference, and increased dopamine release from the substantia nigra in mice, implicating the vagus nerve in gut-induce reward (Han et al. 2018). It remains to be seen whether electrical stimulation of the left cervical vagus nerve using extinction-enhancing parameters is rewarding in rats.

Although extensive evidence indicates that VNS enhances memory consolidation and synaptic plasticity in extinction-related brain circuitry (Clark et al. 1998; Hassert et al. 2004; Chen and Williams 2012; Peña et al. 2014), alternative hypotheses remain plausible. One alternative explanation is counter-conditioning produced by rewarding properties of VNS (Pearce and Dickinson 1975). A second alternative hypothesis is a VNS-induced immediate anxiolytic effect during exposure to conditioned cues, which blunts physiological responses to conditioned cues, diminishing their potency. Here, we describe research designed to determine whether the VNS parameters that enhance extinction are rewarding and to test the role of peripheral effects of VNS on anxiety and extinction of conditioned fear.

\section{Results}

\section{VNS does not induce conditioned place preference}

To examine the potential of VNS to serve as a rewarding stimulus that replaces the negative $\mathrm{CS}$ association with a positive association (counter-conditioning), a conditioned place preference (CPP) test was used to assess potential hedonic effects of VNS. Twelve rats were used in this experiment. Each one was placed in a rectangular Plexiglas apparatus with two distinct, opposing compartments (Fig. 1A), and it was permitted to explore both compartments (places) for 10 min. Time spent in each of the two opposing compartments was used to determine place preference. Paired samples $t$-tests indicated no significant differences across time spent in the two opposite compartments in the CPP apparatus during the initial preference test (before pairing; $\left(t_{(11)}=0.51, P=0.62\right)$. For CPP training, each of the 12 rats was given VNS or sham stimulation in one of the two compartments and the opposite treatment in the other compartment $2 \mathrm{~h}$ later. The compartment that was paired with VNS and the order of VNS and sham stimulation were counterbalanced across the 12 rats. On each of $5 \mathrm{~d}$, one compartment was paired with four 30-sec trains of VNS over the course of $20 \mathrm{~min}$ and the other compartment was paired with four trains of sham stimulation over $20 \mathrm{~min}$. Twenty-four hours after the last day of training, rats were again permitted to explore the open apparatus and time spent in each compartment was measured. No significant differences were seen in time spent in one compartment or the other during the CPP test after pairing $\left(t_{(11)}=0.61\right), P=$ 0.55; Fig. 1C). Naive rats were used in a follow-up CPP test to validate the approach by pairing one side of the CPP apparatus with food. No preference for either side was displayed during the Initial Preference Test (before pairing; $\left(t_{(5)}=0.57, P=0.60\right)$. On the CPP test after food pairing, time spent in the food-paired compartment was significantly greater than time spent in the unpaired compartment (Food Side vs. Empty Side, $t_{(5)}=5.34, P<0.005$; Fig. 1C). Taken together, these results indicate that a valid measure of CPP did not reveal that VNS is rewarding.

\section{Peripheral vagal blockade reverses VNS-induced anxiety reduction}

To examine the role of the peripheral parasympathetic nervous system in VNS effects on anxiety, rats were given intraperitoneal injections of a peripherally acting muscarinic acetylcholine receptor antagonist or saline before they were given a single train

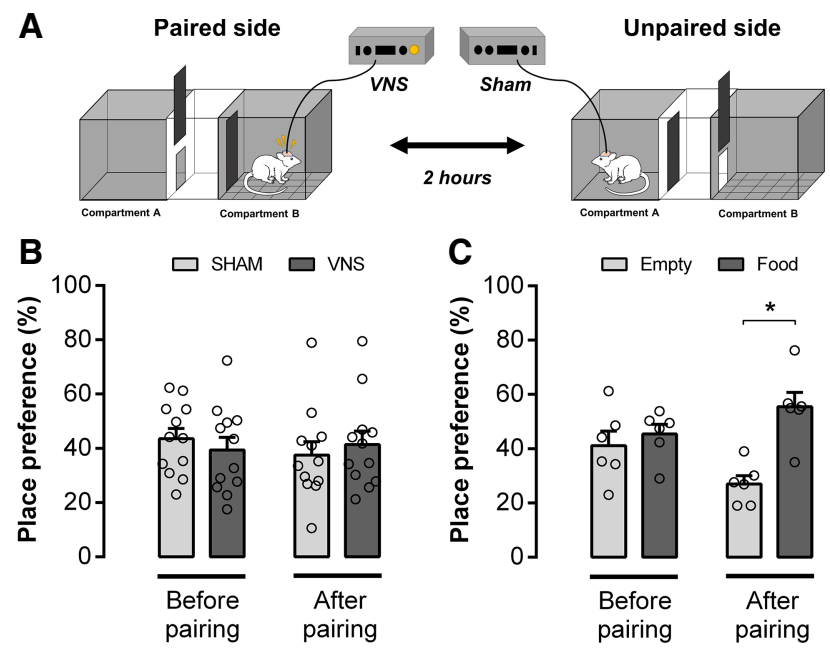

Figure 1. Rats show no preference for the place where VNS was administered. $(A)$ Illustration of the CPP apparatus and pairing procedure. During training, rats were blocked into each of the two opposing compartments for $20 \mathrm{~min} /$ day for $5 \mathrm{~d}$. Four trains of VNS were delivered in the "paired" side of the apparatus and sham stimulation was delivered in the other "unpaired" side on each day, separated by $2 \mathrm{~h}$. On the test trials, both compartments were open and no stimulation was given. Time spent in each compartment was measured and converted to percent of the 20-min test trial. (B) Rats did not show a preference for a place that was associated with VNS. No difference was seen in initial preference for either compartment of the CPP apparatus. After $5 \mathrm{~d}$ of pairing (CPP test), there was still no difference in time spent in the VNS compartment versus time spent in the sham compartment. $(C)$ Rats show a preference for a place that was associated with a food reward. There was no difference in time spent in the two compartments at the initial preference test. However, after pairing one of the chambers with food for $5 \mathrm{~d}$, rats spent significantly more time in the compartment that was previously paired with food versus the unpaired side. Vertical bars represent the mean \pm SEM. Small circles indicate individual data points. $\left(^{*}\right) P<0.05$ for food-paired side in comparison to emptypaired side.

of VNS or sham stimulation, and then tested on the elevated plus maze (EPM). Acetylcholine binding to muscarinic receptors is the principle signaling mechanism between postganglionic parasympathetic nerves and effector targets. The muscarinic antagonist scopolamine methyl-bromide (methyl-scop) does not cross the blood-brain barrier, so it is used as a peripheral "vagal blockade" (Friberg et al. 1989; Carnevali et al. 2011). Rats were given I.P. injections of either saline or methyl-scop $(0.1 \mathrm{mg} / \mathrm{kg}) 15 \mathrm{~min}$ before a single train of VNS or sham stimulation. Ten minutes after stimulation, they were allowed to explore the EPM for $10 \mathrm{~min}$. More time in the open arms was considered an indication of less anxiety (Pellow et al. 1985). Figure 2 depicts the time spent in the open arms. A two-way ANOVA indicated a significant interaction of drug (methyl-scop or saline) versus stimulation (VNS or sham; $\left.F_{(1,32)}=15.04, P=0.0005\right)$ for time spent in the open arms. Main effects of drug $F(1,32)=22.86 ; \mathrm{p}<0.0001)$ and stimulation $F(1,32)=10.78 ; p=0.0025)$ were significant. A Tukey post-hoc test for multiple comparisons revealed significant differences between saline:VNS $(M=248.5, S D=95.56)$ versus saline:sham $(M=102.5$, $S D=35.89)$; saline:VNS versus methyl-scop:sham $(M=84.12, S D=$ 57.01); and saline:VNS versus methyl-scop:VNS $(M=71.99, S D=$ 35.83). Methyl-scop:VNS was not different from saline:sham or methyl-scop:sham and methyl-scop: sham was not different from saline:sham. Consistent with our previous study, VNS was sufficient to increase time spent in the open arms of the EPM in saline-treated rats (Noble et al. 2019), but we did not observe this anxiolytic effect in methyl-scop-treated rats. There was not a significant interaction $\left(F_{(1,32)}=0.08, P=0.7758\right)$, drug $\left(F_{(1,32)}=2.148, P=\right.$ 


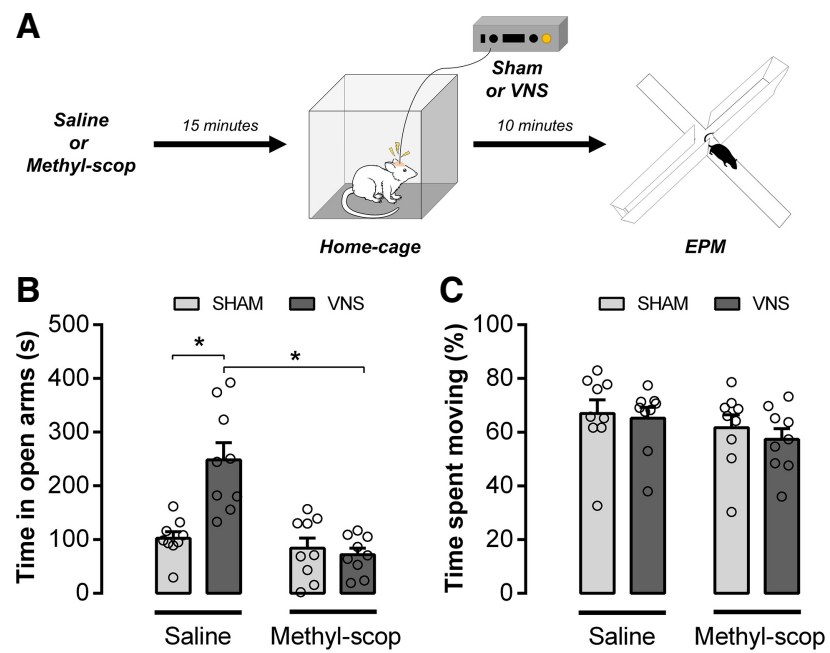

Figure 2. Peripheral vagal blockade reverses VNS-induced reduction in anxiety. (A) Illustration of the systemic injections, stimulation and EPM procedures. Rats were given I.P. injections of either saline or the peripherally acting muscarinic acetylcholine receptor antagonist methyl-scop (0.1 $\mathrm{mg} / \mathrm{kg}$ ). Fifteen minutes after injection, a single noncontingent train of VNS or sham stimulation was administered in the home cage. Rats were then subjected to EPM testing 10 min later. Increased time spent in the open arms indicated a reduction in anxiety. (B) Intraperitoneal administration of Methyl scopolamine (Methyl-scop) before stimulation blocks the anxiolytic effect of VNS. In rats treated with saline, VNS led to a significant increase in time spent in the open arms (vs. sham stimulated rats). However, in rats treated with methyl-scop, this effect was reversed. Methyl-scop-treated rats given VNS showed no difference in time spent in the open arms versus methyl-scop-treated rats given sham stimulation, but saline-treated rats given VNS spent significantly more time in the open arms than methyl-scop-treated rats given VNS. (C) Intraperitoneal administration of Methyl scopolamine (Methyl-scop) before stimulation does not change general locomotion. No significant differences were seen in time spent moving in the EPM. Vertical bars represent the mean \pm SEM. Small circles indicate individual data points. $\left(^{*}\right) P<0.05$.

$0.1525)$, or stimulation $\left(F_{(1,32)}=0.4708, P=0.4976\right)$ effect on time spent moving in the maze. These findings suggest that the VNS-dependent reduction in anxiety requires engagement of peripheral cholinergic receptors.

\section{VNS-induced enhancement of extinction is not affected by blockade of peripheral muscarinic receptors}

Thirty-six rats were given $2 \mathrm{~d}$ of auditory fear conditioning (AFC), followed by a preextinction conditioned fear response test on Day 3. A two-tailed $t$-test revealed no significant differences in preextinction freezing measured $24 \mathrm{~h}$ after fear conditioning $\left(t_{(32)}=\right.$ $1.500, P=0.1435$ ), and before stimulation. To test whether the peripheral actions of VNS are required for VNS-dependent enhancement of fear extinction, methyl-scop or saline was administered 15 min prior to VNS or sham-paired extinction. Figure 3 depicts the effects of pre-VNS methyl-scop in rats submitted to extinction training. A two-way repeated measures ANOVA indicated no significant interaction between factors of drug and stimulation on the Day 5 conditioned fear response test $\left(F_{(1,31)}=0.3594, P=0.5532\right)$. However, there was a main effect of stimulation on postextinction freezing $\left(F_{(1,31)}=52.20, P<0.0001\right)$. Consistent with previous findings, a Tukey's post-hoc test showed a significant decrease in freezing in VNS versus sham rats in both the saline- (sham $M=64.67, S D$ $=13.51$; VNS $M=24.26, S D=17.57$ ) and methyl-scop-treated groups (sham $M=69.87$, $S D=25.94$; VNS $M=22.08, S D=13.47$ ). These findings indicate that VNS-dependent enhancement of fear extinction does not require a peripherally mediated parasympathetic effect.

\section{Discussion}

VNS enhances extinction of conditioned fear in rats. Although there is evidence that VNS promotes plasticity in extinction-related brain networks and enhances consolidation of extinction memory, two alternative hypotheses were investigated here: (1) Does VNS produce a counter-conditioning effect by replacing an aversive unconditioned stimulus with a rewarding unconditioned stimulus? (2) Do descending peripheral vagal fibers contribute to the VNS effects on anxiety and extinction? We found that rats did not show a conditioned preference or aversion to a place that was associated with VNS, suggesting that the VNS parameters used to enhance extinction are not rewarding. Consistent with our previous findings, in saline-treated rats, VNS increased time spent in the open arms of the EPM. This VNS-induced anxiolytic effect was blocked in rats given I.P. injections of the peripherally active muscarinic antagonist methyl-scop. In contrast, administration of methyl-scop did not block the VNS-induced enhancement of extinction of conditioned fear.

There was not a significant difference in time spent in either place in the CPP apparatus, indicating that stimulation of the left cervical vagus is neither rewarding nor aversive in rats. We previously found that VNS enhances extinction even when it is only administered during half of the exposures to the CS (Peña et al. 2013; Noble et al. 2017). Taken together with the present CPP

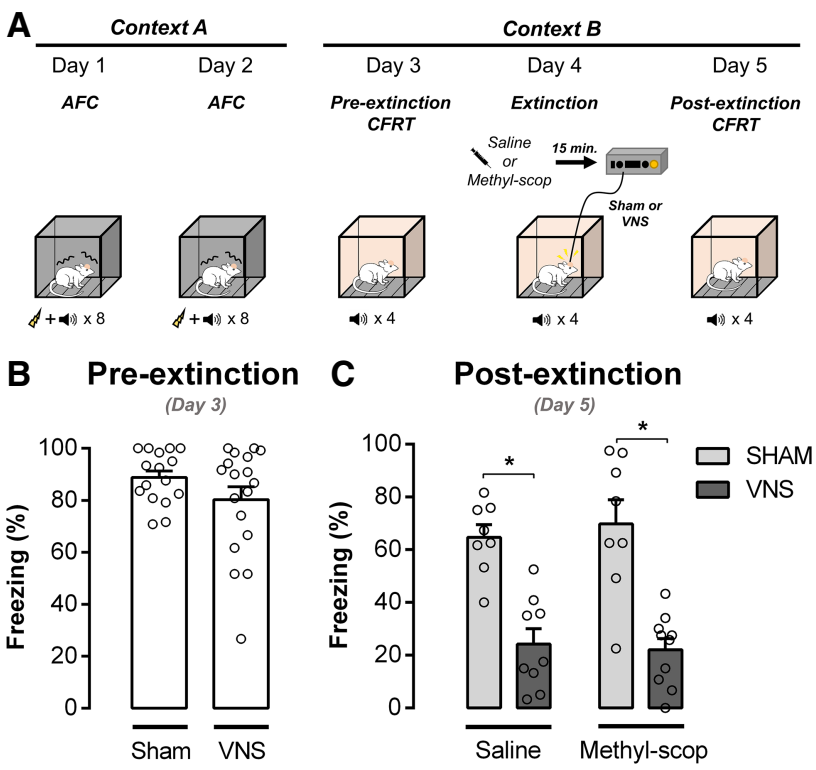

Figure 3. Peripheral vagal blockade does not alter VNS effects on extinction of conditioned fear. $(A)$ Timeline for AFC, conditioned fear response tests (CFRTs), and extinction. Rats were subjected to $2 \mathrm{~d}$ of AFC with eight tone-shock pairings in Context A. Twenty-four hours later, rats underwent a CFRT in Context B to assess fear in the presence of the conditioned auditory stimulus (preextinction). On the following day, methyl-scop was administered 15 min before extinction training (extinction). Another CFRT was given $24 \mathrm{~h}$ later to assess extinction retention (postextinction). (B) Average freezing for Sham and VNS groups during the preextinction phase. There was no difference between groups at the preextinction CFRT. (C) Methyl-scop does not alter VNS-enhanced extinction. VNS-enhanced extinction in saline-treated rats, and in rats treated with methyl-scop. Vertical bars represent the mean \pm SEM. Small circles indicate individual data points. $\left(^{*}\right) P<0.05$ for VNS groups in comparison to the respective sham controls. 
results, these findings do not support the hypothesis that a counter-conditioning effect can explain VNS-induced extinction enhancement.

We found that systemic administration of the peripheral parasympathetic muscarinic receptor antagonist methyl-scop was sufficient to block the anxiolytic effect of VNS on the EPM. These results indicate that the anxiolytic effect of VNS involves peripheral parasympathetic activity, and they support the hypothesis that VNS may reduce conditioned fear responding by interfering with the anxiety response during extinction training. Consistent with this hypothesis, chronic VNS reduces expression of anxiety in rats and in humans (George et al. 2008; Furmaga et al. 2011; Shah et al. 2016) and we previously found that pairing VNS with extinction reduced anxiety and arousal $1 \mathrm{wk}$ later in a rat model of PTSD (Noble et al. 2017). However, administration of VNS that was not given during extinction training did not reduce conditioned fear responding (Peña et al. 2013), indicating that VNS effects on extinction were due to enhancement of extinction-related plasticity rather than a generalized anxiolytic effect. Although it is not likely that the reduction in conditioned fear is due to a lasting anxiolytic effect of VNS, it is possible that VNS administered during exposure to conditioned cues attenuates the conditioned fear response during extinction training.

We hypothesized that the anxiolytic effects of parasympathetic engagement may potentiate the effects of VNS on extinction of conditioned fear because VNS prevents the expected sympathetic nervous system response to the CS. Although peripheral administration of methyl-scop blocked the anxiolytic effect of VNS on the EPM, it had no effect on VNS-induced enhancement of extinction of conditioned fear. Based on the inference that the anxiolytic effects of VNS are dependent on peripheral parasympathetic signaling, the present findings do not support the hypothesis that the anxiolytic effects of VNS are necessary for enhancement of extinction. The present findings, by exclusion, suggest that VNS enhances extinction through the promotion of extinction-related plasticity and consolidation of extinction memory (Clark et al. 1995, 1998, 1999).

The pairing of VNS with training promotes brain plasticity (Engineer et al. 2011; Hays et al. 2013) and VNS increases levels of brain-derived neurotrophic factor (BDNF) in the rat brain (Furmaga et al. 2012). Several studies have demonstrated a role for BDNF in the medial prefrontal cortex (mPFC) in extinction of conditioned fear in rats (Peters et al. 2010; Rosas-Vidal et al. 2014 , 2018). Our previous findings indicate that VNS administration during extinction influences synaptic plasticity in the extinction-related pathway between the infralimbic region of the prefrontal cortex and the basolateral amygdala (Peña et al. 2014), and VNS pairing with extinction increases expression of plasticity-related proteins GluN2b and phosphorylated CaMKII in the basolateral amygdala (Alvarez-Dieppa et al. 2016). GluN2b receptor binding to the endogenous ligand in the basolateral amygdala is essential for extinction of conditioned fear (Sotres-Bayon et al. 2007; Alvarez-Dieppa et al. 2016). This evidence, together with the results presented here, indicate that VNS enhances extinction of conditioned fear by influencing synaptic plasticity that supports the extinction memory.

The United States Food and Drug Administration approved the use of VNS for the prevention of seizures in humans in 1997 and it was approved for the treatment of depression in 2005. Our previous findings indicate that VNS delivered during exposure to $\mathrm{CS}$, in the absence of the unconditioned stimulus, produces targeted plasticity and reverses extinction impairments in rat models of PTSD (Peña et al. 2014; Noble et al. 2017; Souza et al. 2019). Pairing extinction with VNS also attenuates fear renewal and reinstatement and produces lasting benefits on tests of anxiety, arousal, and avoidance symptoms (Noble et al. 2017; Souza et al. 2019).
The present findings indicate that VNS may also counteract the conditioned peripheral sympathetic response experienced in exposure therapy. Some have demonstrated that anxiolytic treatments interfere with progress in exposure therapy (Rothbaum et al. 2014). This may be due to their impairing effects on memory consolidation (Veselis et al. 1997). For example, the benzodiazepine alprazolam produces amnestic effects in normal subjects and in patients with agoraphobia (Block and Berchou 1984; Curran et al. 1994). Unlike these anxiolytic drugs, VNS enhances memory consolidation. Therefore, VNS is an attractive adjuvant to exposure-based therapies because it offers a unique combination of memory consolidation-enhancing and anxiety-reducing effects that may improve tolerability and reduce dropout.

\section{Materials and Methods}

\section{Animals}

All procedures were carried out in accordance with the NIH Guide for the Care and Use of Laboratory Animals and were approved by the Institutional Animal Care and Use Committee of the University of Texas at Dallas. Ninety-four male Sprague-Dawley rats (Charles River) weighing 225-250 g were housed on a $12 \mathrm{~h}$ light-dark cycle (lights on at 7:00 a.m.) with access to food and water ad libitum. To habituate rats to handling, they were handled by an experimenter for $5 \mathrm{~min}$ per day for $5 \mathrm{~d}$ before the start of every experiment.

\section{Cuff electrode production}

Platinum-iridium wire electrodes were glued to the inside of biocompatible micro-renathane cuffs $(1.25 \mathrm{~mm}$ inner diameter, 2.5 $\mathrm{mm}$ outer diameter, $4.0 \mathrm{~mm}$ long). Omnetics four-pin connectors were affixed on top of the skull. These connectors made contact with the platinum-iridium wires in the cuff, and with the cable that was plugged into the head cap, on one end, and an AM systems stimulator on the other end. For details, see Childs et al. (2015).

\section{Vagus nerve stimulation and surgery}

The left vagus nerve was located at the cervical level in anesthetized rats $(2 \%$ isofluorane at an oxygen flow rate of $600-800 \mathrm{~mL} / \mathrm{min})$ and isolated from other tissue. The platinum-iridium electrode cuff was wrapped around the nerve. Electrode leads were tunneled subcutaneously to the top of the head and connected to an Omnetics connector that was affixed to the skull with acrylic. To test the efficacy of the cuff electrode after implantation, current $(0.8 \mathrm{~mA}, 1 \mathrm{~s})$ was applied to the cuff electrode while the rat was still anesthetized and breathing rate was observed. A brief cessation of breathing following VNS was used to indicate that the cuff electrode was properly placed and functioning. If the cessation of breathing was not observed, the cuff was adjusted or replaced. For sham rats, the vagus nerve was isolated from the other tissue and an Omnetics connector was affixed to the skull, but the platinum electrode was not implanted. Rats were given 1 wk to recover from surgery before training and testing.

For VNS administration, the head cap was connected to the stimulator for both VNS- and sham-treated rats. For a visual demonstration of surgical and VNS details, see Childs et al. (2015). Stimulation was delivered at $0.4 \mathrm{~mA}, 20 \mathrm{~Hz}, 100 \mu \mathrm{sec}$ pulse width, for a duration of $30 \mathrm{sec}$. These parameters were previously used to enhance extinction of conditioned fear in rats (Noble et al. 2017, 2019).

\section{Conditioned place preference (VNS vs. sham)}

Twelve rats were used for this experiment. During an initial place preference test, each rat was placed in a rectangular Plexiglas apparatus $(72 \times 25 \mathrm{~cm}$; Allied Plastics LLC; Fig. 1$)$. The walls of the apparatus were $40 \mathrm{~cm}$ tall and the top was open. The apparatus was divided into three small compartments by two removable inner 
walls. With the walls inserted, the middle white Plexiglas section was $12 \times 25 \mathrm{~cm}$ and the two black Plexiglas side compartments were $30 \times 25 \mathrm{~cm}$. To make the two side compartments distinguishable, the floor of one of the two side compartments was made of a clear Plexiglas insert with holes in a honeycomb configuration.

Rats were habituated to VNS in three 20-min sessions where they were given four 30 -sec trains in their home cages. On the third day, rats were habituated to the CPP apparatus. During a 10-min habituation trial, they were given free access to all three sections. A camera mounted over the apparatus recorded time spent in each compartment. This measure was used to examine whether rats preferred a specific location prior to pairing the place with VNS or sham stimulation.

For the next $5 \mathrm{~d}$, rats were given VNS in one compartment of the CPP apparatus and sham stimulation in the other compartment. Each rat served as its own control and received both VNS and sham stimulation in respective compartments. The VNS/ sham compartments were counterbalanced so six rats received VNS and six rats received sham stimulation in each of the two compartments, but all 12 rats had VNS in one compartment and sham stimulation in the other. Assignment of VNS compartment and the order in which rats received VNS or sham stimulation was counterbalanced, so a total of three rats started in Compartment A with VNS, three rats started in Compartment B with VNS, three rats started in Compartment A with sham stimulation, and three rats started in Compartment B with sham stimulation. The compartment paired with VNS was not selected based on initial preference because, although our hypothesis was that VNS may be rewarding, there was also a possibility that VNS could be aversive. Therefore, we avoided biasing the results in either direction. For each trial, a cable was attached to the cuff electrode on the rat's head cap, and the rat was blocked into one of the CPP compartments for $20 \mathrm{~min}$. For the sham condition, no stimulation was delivered. For the VNS condition, the vagus nerve was stimulated four times, with a 120 - to 240 -sec interval between stimulus delivery, to match the VNS administration parameters used during extinction trials in our previous studies (Peña et al. 2013; Noble et al. 2017). Sham and VNS trials were given on the same day, $2 \mathrm{~h}$ apart.

The postpreference test was administered $24 \mathrm{~h}$ after the fifth day of place pairing. During the test trial, rats were placed in the middle section with the interior walls removed, allowing rats to roam freely inside the apparatus for $10 \mathrm{~min}$. No stimulation was administered on test trials. Time spent in each of the compartments was again recorded using ANYMaze software. A paired sample $t$-test was used to determine if rats showed a significant preference for the place where they previously received VNS or sham stimulation.

\section{Conditioned place preference (food vs. no food)}

To validate the CPP protocol, six additional rats underwent a control test using an appetitive stimulus (Froot Loops). These rats did not undergo surgery. Six Froot Loops were placed in each home cage every day for $5 \mathrm{~d}$. For $3 \mathrm{~d}$, rats were given free access to all of the compartments of the CPP apparatus for a total of $10 \mathrm{~min}$. On the third day, the time spent in each compartment was recorded. During CPP training, one compartment contained six Froot Loops and the other contained no food. Again, every rat was exposed for $20 \mathrm{~min}$ to each side every day for $5 \mathrm{~d}$. The side that was paired with Froot Loops was counterbalanced. Twenty-four hours after the fifth day of place pairing, interior walls were removed and rats were given free access to all compartments of the CPP apparatus for $10 \mathrm{~min}$. No food was present on the maze.

\section{Elevated plus maze}

Rats were placed in the central part of an elevated plus-shaped maze with two walls (50 cm tall) on opposing arms and no walls on the other two arms. The arms were $10 \mathrm{~cm}$ wide, $50 \mathrm{~cm}$ long, and elevated $55 \mathrm{~cm}$ from the ground. During a 10-min test, time spent in the open arms, time spent in the closed arms, and time spent in the center of the maze were recorded. Greater time spent in the open arms was used as an indication of reduced anxiety and less time spent in the open arms was considered a measure of increased anxiety (Pellow et al. 1985; Walf and Frye 2007).

Thirty-six rats were treated with intraperitoneal injections of $0.1 \mathrm{mg} / \mathrm{kg}$ methyl-scop dissolved in sterile saline, or saline alone. The dose of methyl-scop was selected from a preliminary dose-response study indicating that $0.1 \mathrm{mg} / \mathrm{kg}$ (without VNS or sham stimulation) was the highest dose that did not affect EPM performance. Fifteen minutes after the injection, rats were given VNS ( $n=9$ /group) or sham ( $n=9$ /group) stimulation in their home cages and then placed in the center platform of an EPM 10 min later.

\section{Auditory fear conditioning}

Thirty-four rats were exposed to four pretones $(9 \mathrm{kHz}, 70 \mathrm{~dB}$, lasting $30 \mathrm{sec}$ ) in order to determine baseline levels of freezing in response to the sound. Following these four tone exposures, eight tones were played and a single $1 \mathrm{sec}, 0.4 \mathrm{~mA}$ footshock overlapped with each tone. The timing of the footshock was randomized during the 30-sec tone presentation and the tones were presented at a random inter-stimulus interval of between 120 and 240 sec. Eight tone-shock pairings were given again $24 \mathrm{~h}$ later. No pretones were given on the second day of fear conditioning. All AFC occurred in Context A (electric grid floor, no olfactory cue). A conditioned fear response test was given $24 \mathrm{~h}$ after the $2 \mathrm{~d}$ of AFC. Fear responses to the CS were measured in Context B (Context A chamber with Plexiglas insert on floor and addition of peppermint oil odor cue). The 30-sec tone was presented four times with an interval of 120-240 sec and no footshock was administered. Freezing during tone presentation was recorded using a camera located on the side wall of the training apparatus. Two independent experimenters who were blind to conditions measured freezing in response to the tone and scores were averaged.

\section{Anxiolytic contributions to extinction}

Extinction trials were given in Context B on the following day. Rats received an intraperitoneal injection of either methyl-scop $(0.1$ $\mathrm{mg} / \mathrm{ml} ; n=8-9 /$ group) or saline ( $n=8-9 /$ group). Fifteen minutes following the injection, rats underwent extinction training where four presentations of the CS were paired with VNS, or sham stimulation, as in our previous reports (Peña et al. 2014; Childs et al. 2015; Alvarez-Dieppa et al. 2016). The day after extinction training, conditioned fear responses to the CS were measured again in Context B (Fig. 3a).

\section{Statistical analyses}

Time spent in the paired compartment during the CPP tests, time spent in the open arms and moving on the EPM, and time spent freezing in the extinction context were converted to percentages of total exposure time. CPP results were analyzed using a paired sample $t$-test. A two-tailed $t$-test was used to compare conditioned fear responses (\% time spent freezing) in sham and VNS groups before extinction training. Data for peripheral vagal blockade experiments were analyzed using a two-way ANOVA to test for significant effects of drug (methyl-scop vs. saline) and stimulation (VNS vs. sham), and an interaction between the two variables, followed by a Tukey's post-hoc test for multiple comparisons. Statistically significant effects were defined as those with $P$ values that were $<0.05$.

Two rats were excluded from analysis for failure to express conditioned fear following AFC (freezing less than 50 percent of exposure time). Exclusion of these rats did not alter statistical comparisons.

\section{Competing interest statement}

This work has not been published and has not been submitted for publication elsewhere while under consideration. L.J.N., A.C., K.K. C., and R.R.S. declare no potential conflicts of interest. C.K.M. is an 
author of a patent entitled "Enhancing Fear Extinction using Vagus Nerve Stimulation."

\section{Acknowledgments}

We would like to thank Phillip Gonzalez and Michelle Schmutz for their work manufacturing cuff electrodes. We thank Eva Recoussine, Brandon Currie, Kinnari Karia, and Amber Mawji for their assistance conducting behavioral studies. This work was sponsored by the Defense Advanced Research Projects Agency (DARPA) Biological Technologies Office (BTO) Electrical Prescriptions (ElectRx) program under the auspices of Dr. Doug Weber and Dr. Eric Van Gieson and through the Space and Naval Warfare Systems Center, Pacific. Grant/Contract No. DARPA-BAA-14-38 and DARPA-BAA-15-06 and by the NIMH (MH099655).

\section{References}

Alvarez-Dieppa AC, Griffin K, Cavalier S, McIntyre CK. 2016. Vagus nerve stimulation enhances extinction of conditioned fear in rats and modulates Arc protein, CaMKII, and GluN2B-containing NMDA receptors in the basolateral amygdala. Neural Plast 2016: 1-11. doi:10 $.1155 / 2016 / 4273280$

Block RI, Berchou R. 1984. Alprazolam and lorazepam effects on memory acquisition and retrieval processes. Pharmacol Biochem Behav 20: 233241. doi:10.1016/0091-3057(84)90248-X

Boschen MJ, Neumann DL, Waters AM. 2009. Relapse of successfully treated anxiety and fear: theoretical issues and recommendations for clinical practice. Aust N Z J Psychiatry 43: 89-100. doi:10.1080/ 00048670802607154

Bouton ME. 1988. Context and ambiguity in the extinction of emotional learning: implications for exposure therapy. Behav Res Ther 26: 137-149. doi:10.1016/0005-7967(88)90113-1

Cahill L, Alkire MT. 2003. Epinephrine enhancement of human memory consolidation: interaction with arousal at encoding. Neurobiol Learn Mem 79: 194-198. doi:10.1016/S1074-7427(02)00036-9

Carnevali L, Bondarenko E, Sgoifo A, Walker FR, Head GA, Lukoshkova EV, Day TA, Nalivaiko E. 2011. Metyrapone and fluoxetine suppress enduring behavioral but not cardiac effects of subchronic stress in rats. Am J Physiol Regul Integr Comp Physiol 301: R1123-R1131. doi:10.1152/ ajpregu.00273.2011

Chen CC, Williams CL. 2012. Interactions between epinephrine, ascending vagal fibers, and central noradrenergic systems in modulating memory for emotionally arousing events. Front Behav Neurosci 6: 35. doi:10.3389/ fnbeh.2012.00035

Childs JE, Alvarez-Dieppa AC, McIntyre CK, Kroener S. 2015. Vagus nerve stimulation as a tool to induce plasticity in pathways relevant for extinction learning. J Vis Exp 21: e53032. doi:10.3791/53032

Clark KB, Krahl SE, Smith DC, Jensen RA. 1995. Post-training unilateral vagal stimulation enhances retention performance in the rat. Neurobiol Learn Mem 63: 213-216. doi:10.1006/nlme.1995.1024

Clark KB, Smith DC, Hassert DL, Browning RA, Naritoku DK, Jensen RA. 1998. Posttraining electrical stimulation of vagal afferents with concomitant vagal efferent inactivation enhances memory storage processes in the rat. Neurobiol Learn Mem 70: 364-373. doi:10.1006/ nlme.1998.3863

Clark KB, Naritoku DK, Smith DC, Browning RA, Jensen RA. 1999. Enhanced recognition memory following vagus nerve stimulation in human subjects. Nat Neurosci 2: 94-98, doi:10.1038/4600

Curran HV, Bond A, O'Sullivan G, Bruce M, Marks I, Lelliot P, Shine P, Lader M. 1994. Memory functions, alprazolam and exposure therapy: a controlled longitudinal study of agoraphobia with panic disorder. Psychol Med 24: 969-976. doi:10.1017/S0033291700029056

Davis M, Ressler K, Rothbaum BO, Richardson R. 2006. Effects of D-cycloserine on extinction: translation from preclinical to clinical work. Biol Psychiatry 60: 369-375. doi:10.1016/j.biopsych.2006.03.084

Engineer ND, Riley JR, Seale JD, Vrana WA, Shetake JA, Sudanagunta SP, Borland MS, Kilgard MP. 2011. Reversing pathological neural activity using targeted plasticity. Nature 470: 101-104. doi:10.1038/ nature09656

Friberg P, Karlsson B, Nordlander M. 1989. Autonomic control of the diurnal variation in arterial blood pressure and heart rate in spontaneously hypertensive and Wistar-Kyoto rats. J Hypertens 7: 799-807. doi:10 .1097/00004872-198910000-00005

Furmaga H, Shah A, Frazer A. 2011. Serotonergic and noradrenergic pathways are required for the anxiolytic-like and antidepressant-like behavioral effects of repeated vagal nerve stimulation in rats. Biol Psychiatry 70: 937-945. doi:10.1016/j.biopsych.2011.07.020
Furmaga H, Carreno FR, Frazer A. 2012. Vagal nerve stimulation rapidly activates brain-derived neurotrophic factor receptor TrkB in rat brain. PLoS One 7: e34844. doi:10.1371/journal.pone.0034844

Garcia H, Kelley L, Rentz T, Lee S. 2011. Pretreatment predictors of dropout from cognitive behavioral therapy for PTSD in Iraq and Afghanistan war veterans. Psychol Serv 8: 1-11. doi:10.1037/a0022705

George MS, Ward HE, Ninan PT, Pollack M, Nahas Z, Anderson B, Kose S, Howland RH, Goodman WK, Ballenger JC. 2008. A pilot study of vagus nerve stimulation (VNS) for treatment-resistant anxiety disorders. Brain Stimul 1: 112-121. doi:10.1016/j.brs.2008.02.001

Gold PE, van Buskirk RB, McGaugh JL. 1975. Effects of hormones on time-dependent memory storage processes. Prog Brain Res 42: 210-211. doi:10.1016/S0079-6123(08)63665-1

Gold PE, van Buskirk R, Haycock JW. 1977. Effects of posttraining epinephrine injections on retention of avoidance training in mice. Behav Biol 20: 197-204. doi:10.1016/S0091-6773(77)90760-X

Han W, Tellez LA, Perkins MH, Perez IO, Qu T, Ferreira J, Ferreira TL, Quinn D, Liu ZW, Gao XB, et al. 2018. A neural circuit for gut-induced reward. Cell 175: 887-888. doi:10.1016/j.cell.2018.10.018

Hassert DL, Miyashita T, Williams CL. 2004. The effects of peripheral vagal nerve stimulation at a memory-modulating intensity on norepinephrine output in the basolateral amygdala. Behav Neurosci 118: 79-88. doi:10.1037/0735-7044.118.1.79

Hays SA, Rennaker RL, Kilgard MP. 2013. Targeting plasticity with vagus nerve stimulation to treat neurological disease. Prog Brain Res 207: 275299. doi:10.1016/B978-0-444-63327-9.00010-2

Liang KC, Juler RG, McGaugh JL. 1986. Modulating effects of posttraining epinephrine on memory: involvement of the amygdala noradrenergic system. Brain Res 368: 125-133. doi:10.1016/0006-8993(86)91049-8

Miyashita T, Williams CL. 2006. Epinephrine administration increases neural impulses propagated along the vagus nerve: role of peripheral $\beta$-adrenergic receptors. Neurobiol Learn Mem 85: 116-124. doi:10.1016/j .nlm.2005.08.013

Najavits LM. 2015. The problem of dropout from "gold standard" PTSD therapies. F1000Prime Rep 7: 43. doi:10.12703/P7-43

Noble LJ, Gonzalez IJ, Meruva VB, Callahan KA, Belfort BD, Ramanathan KR, Meyers E, Kilgard MP, Rennaker RL, McIntyre CK. 2017. Effects of vagus nerve stimulation on extinction of conditioned fear and post-traumatic stress disorder symptoms in rats. Transl Psychiatry 7: e1217. doi:10.1038/tp.2017.191

Noble LJ, Souza RR, McIntyre CK. 2018. Vagus nerve stimulation as a tool for enhancing extinction in exposure-based therapies. Psychopharmacology 236: 355-367. doi:10.1007/s00213-018-4994-5

Noble LJ, Meruva VB, Hays SA, Rennaker RL, Kilgard MP, McIntyre CK. 2019 Vagus nerve stimulation promotes generalization of conditioned fear extinction and reduces anxiety in rats. Brain Stimul 12: 9-18. doi:10 $.1016 /$ j.brs.2018.09.013

Pearce JM, Dickinson A. 1975. Pavlovian counterconditioning: changing the suppressive properties of shock by association with food. J Exp Psychol Anim Behav Process 1: 170-177. doi:10.1037/0097-7403.1.2.170

Pellow S, Chopin P, File SE, Briley M. 1985. Validation of open:closed arm entries in an elevated plus-maze as a measure of anxiety in the rat. $J$ Neurosci Methods 14: 149-167. doi:10.1016/0165-0270(85)90031-7

Peña DF, Engineer ND, McIntyre CK. 2013. Rapid remission of conditioned fear expression with extinction training paired with vagus nerve stimulation. Biol Psychiatry 73: 1071-1077. doi:10.1016/j.biopsych 2012.10.021

Peña DF, Childs JE, Willett S, Vital A, McIntyre CK, Kroener S. 2014. Vagus nerve stimulation enhances extinction of conditioned fear and modulates plasticity in the pathway from the ventromedial prefrontal cortex to the amygdala. Front Behav Neurosci 8: 327. doi:10.3389/fnbeh 2014.00327

Peters J, Dieppa-Perea LM, Melendez LM, Quirk GJ. 2010. Induction of fear extinction with hippocampal-infralimbic BDNF. Science 328: 12881290. doi:10.1126/science.1186909

Powers MB, Smits JA, Otto MW, Sanders C, Emmelkamp PM. 2009. Facilitation of fear extinction in phobic participants with a novel cognitive enhancer: a randomized placebo controlled trial of yohimbine augmentation. J Anxiety Disord 23: 350-356. doi:10.1016/j.janxdis.2009 .01 .001

Rauch SA, Eftekhari A, Ruzek JI. 2012. Review of exposure therapy: a gold standard for PTSD treatment. J Rehabil Res Dev 49: 679-687. doi:10 1682/JRRD.2011.08.0152

Ressler KJ, Rothbaum BO, Tannenbaum L, Anderson P, Graap K, Zimand E, Hodges L, Davis M. 2004. Cognitive enhancers as adjuncts to psychotherapy: use of D-cycloserine in phobic individuals to facilitate extinction of fear. Arch Gen Psychiatry 61: 1136-1144. doi:10.1001/ archpsyc.61.11.1136

Rosas-Vidal LE, Do-Monte FH, Sotres-Bayon F, Quirk GJ. 2014. Hippocampal-prefrontal BDNF and memory for fear extinction. Neuropsychopharmacology 39: 2161-2169. doi:10.1038/npp.2014.64 
Rosas-Vidal LE, Lozada-Miranda V, Cantres-Rosario Y, Vega-Medina A, Melendez L, Quirk GJ. 2018. Alteration of BDNF in the medial prefrontal cortex and the ventral hippocampus impairs extinction of avoidance. Neuropsychopharmacology 43: 2636-2644. doi:10.1038/ s41386-018-0176-8

Rothbaum BO, Price M, Jovanovic T, Norrholm SD, Gerardi M, Dunlop B, Davis M, Bradley B, Duncan EJ, Rizzo A, et al. 2014. A randomized, double-blind evaluation of D-cycloserine or alprazolam combined with virtual reality exposure therapy for posttraumatic stress disorder in Iraq and Afghanistan War veterans. Am J Psychiatry 171: 640-648. doi:10 .1176/appi.ajp.2014.13121625

Schottenbauer MA, Glass CR, Arnkoff DB, Tendick V, Gray SH. 2008. Nonresponse and dropout rates in outcome studies on PTSD: review and methodological considerations. Psychiatry 71: 134-168. doi:10.1521/ psyc.2008.71.2.134

Shah AP, Carreno FR, Wu H, Chung YA, Frazer A. 2016. Role of TrkB in the anxiolytic-like and antidepressant-like effects of vagal nerve stimulation: comparison with desipramine. Neuroscience 322: 273-286. doi:10.1016/j.neuroscience.2016.02.024

Sotres-Bayon F, Bush DE, LeDoux JE. 2007. Acquisition of fear extinction requires activation of NR2B-containing NMDA receptors in the lateral amygdala. Neuropsychopharmacology 32: 1929-1940. doi:10.1038/sj.npp .1301316

Souza RR, Robertson NM, Pruitt DT, Gonzales PA, Hays SA, Rennaker RL, Kilgard MP, McIntyre CK. 2019. Vagus nerve stimulation reverses the extinction impairments in a model of PTSD with prolonged and repeated trauma. Stress 23: 1-12. doi:10.1080/10253890.2019.1602604

Vervliet B, Craske MG, Hermans D. 2013. Fear extinction and relapse: state of the art. Аппи Rev Clin Psychol 9: 215-248. doi:10.1146/ annurev-clinpsy-050212-185542

Veselis RA, Reinsel RA, Feshchenko VA, Wroński M. 1997. The comparative amnestic effects of midazolam, propofol, thiopental, and fentanyl at equisedative concentrations. Anesthesiology 87: 749-764. doi:10.1097/ 00000542-199710000-00007

Walf AA, Frye CA. 2007. The use of the elevated plus maze as an assay of anxiety-related behavior in rodents. Nat Protoc 2: 322-328. doi:10.1038/ nprot.2007.44

Received January 29, 2019; accepted in revised form May 7, 2019. 


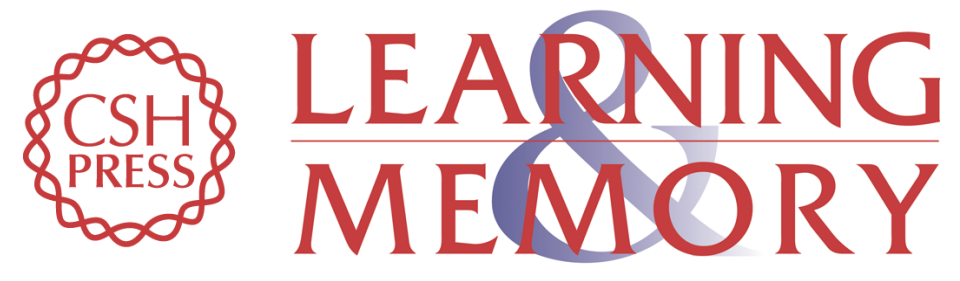

\section{Peripheral effects of vagus nerve stimulation on anxiety and extinction of conditioned fear in rats}

Lindsey J. Noble, Ashleigh Chuah, Kathleen K. Callahan, et al.

Learn. Mem. 2019, 26:

Access the most recent version at doi:10.1101/Im.048447.118

References This article cites 48 articles, 1 of which can be accessed free at:

http://learnmem.cshlp.org/content/26/7/245.full.html\#ref-list-1

Creative This article is distributed exclusively by Cold Spring Harbor Laboratory Press for the

Commons

first 12 months after the full-issue publication date (see

License http://learnmem.cshlp.org/site/misc/terms.xhtml). After 12 months, it is available under a Creative Commons License (Attribution-NonCommercial 4.0 International), as described at http://creativecommons.org/licenses/by-nc/4.0/.

Email Alerting Receive free email alerts when new articles cite this article - sign up in the box at the Service top right corner of the article or click here. 